\title{
EAR RECONSTRUCTION SURGERY: OUTCOME ANALYSIS OF 108 PATIENTS
}

\author{
Ghazanfar Ali, Sikandar Ali Khan, Habib Ur Rehman, Atif Rafique, Ghulam Fareed, Maqbool Raza* \\ Combined Military Hospital Multan/National University of Medical Sciences (NUMS) Pakistan, ${ }^{*}$ Combined Military Hospital Quetta/National University of \\ Medical Sciences (NUMS) Pakistan
}

\section{ABSTRACT}

Objective: To find out the outcome of the ear Reconstruction and its association with improvement in psychological wellbeing along with physical benefits.

Study Design: A cross-sectional study.

Place and Duration of Study: Department of Plastic Surgery and ENT, Combined Military Hospital Quetta and Multan in liaison with the department of Psychiatry, from Jan 2017 to Jan 2021.

Methodology: A sample size of 108 was estimated while keeping level of significance 5\%, confidence level $90 \%$, estimated true proportion $63 \%$ based on the observation made in the study by Steffen, and $5 \%$ of absolute precision. Specific performas were filled by the patient pre and post operatively and data analysis was performed using SPSS-20.

Results: The mean age was $20 \pm 8.75$ years with a range of $12-29$ years. Thirteen $(11.11 \%)$ were male and ninety-five $(87.8 \%)$ were females, 14 (12.9\%) were married, 94 (86\%) were un-married and all (100\%) had social support. Fifty-two (48.1\%) had primary education. Ninety-four $(94 \%)$ were un-employed. Fifty-five $(50.9 \%)$ of participants had congenital ear defect. Ninetyeight $(90.7 \%)$ of the participants showed confidence in surgical procedure and would go for the same procedure if required, 5 $(4.6 \%)$ said no to the same procedure while $8(7.4 \%)$ did not know whether to opt for same procedure.

Conclusion: Ear Reconstruction is a very rewarding procedure for surgeon and patients. Apart from aesthetic and functional improvement it also enhances the self-esteem of the patients.

Keywords: Age, Association, Cognitive impairment, Gender, Social support.

How to Cite This Article: Ali G, Khan SA, Rehman H, Rafique A, Fareed G, Raza M.Ear Reconstruction Surgery: Outcome Analysis of 108 Patients. Pak Armed Forces Med J 2021; 71(Suppl-3): S565-568. Doi: https://doi.org/10.51253/pafmj.v1i1.7939

This is an Open Access article distributed under the terms of the Creative Commons Attribution License (https://creativecommons.org/licenses/by-nc/4.0/), which permits unrestricted use, distribution, and reproduction in any medium, provided the original work is properly cited.

\section{INTRODUCTION}

In the field of plastic surgery ear defects have always posed challenges to the plastic surgeons that endeavor to achieve impeccable cosmetic results in facial reconstruction surgery. ${ }^{1-2}$ Ear reconstruction proves rewarding and satisfying experience to both surgeon and patient when surgeon is well aware of the fact that each and every ear defect is unique in itself, keeps in mind not only the size and location of defect but also the quality and amount of surrounding tissue available, past experience and last but not the least what patient prefers. $^{3}$ Primarily surgeons aim at achieving symmetry between two ears therefore it is imperative to keep in mind the three dimensional out look of ear that is to be constructed in comparison to unaffected normal ear. ${ }^{4}$ Ear defects can be congenital or acquired like trauma, burns, tumors, piercing, scar, inflammatory or allergic. ${ }^{5}$ Congenital defects range from Grade I to Grade III including Microtia changes long with middle ear malformations and aural atresia. ${ }^{6}$ Fortunately, Microtia is well classified but on the other hand defects

Correspondence: Dr Ghazanfar Ali, Department of Plastic Surgery, Combined Military Hospital, Multan Pakistan caused by trauma are less well defined but full thickness traumatic ear defects are either classified anatomically or classified as defects of cutaneous coverage with or without intact cartilage and full thickness defects. condition of Costal cartilagegrafts or use of prosthesis are possible options for the reconstruction of ear but it all depends on the pathology, condition of the local tissue and mutual preference of surgeon and patient to ultimately improve the quality of life of patient. ${ }^{7-9}$ Whatever the type of ear defect is there before embarking upon ear reconstruction it is imperative for a surgeon to foresee and appreciate the post-operative complications, future concerns, nature and extent of post-operative scar which may have aesthetic and psychological consequences such as satisfaction with the procedure, self-esteem along with impact on social and occupational functioning. ${ }^{10}$ Like every surgical procedure ear reconstruction surgery can also lead to certain complications such as hematoma, bleeding, infection, pain, scaring and even there is chance of revision surgery.

Few studies have paid attention to psychological impact of ear defects and ameliorating effects of ear reconstruction surgery on the patients. This study 
endeavors to find association of ear reconstruction surgery with improvement in psychological wellbeing along with physical benefits.

\section{METHODOLOGY}

This cross-sectional study was conducted at the department of plastic surgery and ENT department, Combined Military Hospital Quetta and Multan in liaison with the department of Psychiatry from Jan 2017 to Jan 2021. A sample size of 108 was estimated while keeping level of significance 5\%, confidence level 90\%, estimated true proportion $63 \%$ based on the observation made in the study by Steffen, and $5 \%$ of absolute precision. ${ }^{11}$

A total of 108 subjects were included by using consecutive non-probability sampling after the approval from the ethical committee. After written consent, all inductees were explained purpose of the study and confidentiality was ensured.

Inclusion Criteria: Patients with ear defect undergoing ear reconstruction $b$ ) able to follow the study instructions.

Exclusion Criteria: Other medical history b) concomitant other neurological disorder (as both of these can lead to secondary depression) c) Past psychiatric history or substance abuse.

Participants were asked to fill in the questionnaire twice pre-operatively and post-operatively. This questionnaire consisted items assessing ability to perform, self-esteem and social support along with future concerns and apprehensions about possible complications, prolonged stay in hospital, cosmetic results of surgery and to assess the level of satisfaction with procedure participants were asked whether they will opt for same procedure if again required. Detailed psychiatric interview was conducted to diagnosis depression and Anxiety based on the diagnostic criteria given by the International Classification of Diseases version. ${ }^{10}$

Data analysis was performed using Statistical Package for Social Sciences (SPSS) versin 20. The data were described as averages (mean $\pm \mathrm{SD}$ ) and percentages $\mathrm{n}(\%)$. For statistical analysis, Pearson's chi square test was used. All the inferences were made at $95 \%$ confidence interval and $p$-value of $\leq 0.05$ were considered significant.

\section{RESULTS}

A total of 108 patients were included in this study. The mean age was $20 \pm 8.75$ years with a range of $12-29$ years. Thirteen $(11.11 \%)$ were male and 95 (87.8\%) were females, 14 (12.9) were married, 94 (86\%) were un-married and all (100\%) had social support. Fifty-two $(48.1 \%)$ had primary education and only $7(6.3 \%)$ were graduate participants. Ninety-four $(94 \%)$ were un-employed while only $14(13 \%)$ were employed. Fifty-five $(50.9 \%)$ of participants had congenital ear defect, 6 (5.5\%) had ear defect due to dog bite, 13 $(12.04 \%)$ had ear defect due to tumor, 19 (17.59\%) due to trauma and only $1(1 \%)$ developed ear defect due to infection, $98(90.7 \%)$ of the participants showed confidence in surgical procedure and would go for the same procedure if required, $5(4.6 \%)$ said no to the same procedure while $8(7.4 \%)$ did not know whether to opt for same procedure or not. Regarding future concerns $95(88.2 \%)$ of participants were worried about postoperative complications, 98 (91.3\%) had cosmetic concerns, 68 (61.8\%)worried about development of scar while $36(37.7 \%)$ had concerns about prolonged stay at hospital after surgery as shown in Table-I.

Table-I: descriptive analysis $(\mathrm{n}=108)$.

\begin{tabular}{|c|c|c|}
\hline Variable & n & Percentage \\
\hline Age (Mean \pm SD) & \multicolumn{2}{|c|}{$20 \pm 8.75$} \\
\hline \multicolumn{3}{|l|}{ Gender } \\
\hline Male & 13 & 11.11 \\
\hline Female & 95 & 87.8 \\
\hline \multicolumn{3}{|l|}{ Marital Status } \\
\hline Married & 14 & 12.9 \\
\hline Unmarried & 94 & 86 \\
\hline \multicolumn{3}{|l|}{ Educational Status } \\
\hline Primary & 52 & 48.1 \\
\hline Secondary & 30 & 28.33 \\
\hline Undergraduate & 19 & 17.25 \\
\hline Graduate & 7 & 6.3 \\
\hline \multicolumn{3}{|l|}{ Occupational Status } \\
\hline Employed & 14 & 13 \\
\hline Unemployed & 94 & 87 \\
\hline \multicolumn{3}{|l|}{ Ear Defect } \\
\hline Congenital & 55 & 50.9 \\
\hline Bites & 6 & 5.5 \\
\hline Tumors & 13 & 12.04 \\
\hline Trauma & 19 & 17.59 \\
\hline Burn & 12 & 11.11 \\
\hline Infections & 3 & 2.78 \\
\hline Family Support & 108 & 100 \\
\hline \multicolumn{3}{|l|}{ Would OPT for same op } \\
\hline Yes & 98 & 90.7 \\
\hline No & 5 & 4.6 \\
\hline Do Not Know & 8 & 7.4 \\
\hline \multicolumn{3}{|l|}{ Future Concerns $(n=108)$} \\
\hline Complications & 95 & 88.2 \\
\hline Cosmetic results & 98 & 91.3 \\
\hline Scar & 68 & 61.8 \\
\hline Prolonged stay in Hospital & 36 & 33.7 \\
\hline
\end{tabular}

Twenty-five $(23.4 \%)$ of the participants experienced pain and itching after surgery, 5 (4.2\%) developed 
hematoma/bleeding, 3 (2.4\%) developed post-operative scar, $4(2.8 \%)$ of participants faced the complication of revision surgery as shown in Table-II.

When pre-operative data was compared with post-operative data of future concerns of complications, cosmetic concerns, scar development, prolonged hospital stay and social inhibition, significant difference was seen $(p=0.00)$ as shown in Table-III. Pre-operatively $85(79.5 \%)$ had anxiety and $7(10.1 \%)$ had depression when compared post-operatively anxiety remained only among $25(23.5 \%)$ and depression among 4 $(3.6 \%)$ of the participants $(p=0.01$ and $p=0.02$ for anxiety and depression respectively) as shown in Table-III.

Table-II: Post-operative complications $(n=108)$.

\begin{tabular}{l|c|c}
\hline Complication & Number (n) & Percentage (\%) \\
\hline Hematoma/Bleeding & 5 & 4.2 \\
\hline Infection & 1 & 1 \\
\hline Wound healing & 3 & 2.4 \\
\hline Suture & 2 & 2 \\
\hline Scaring & 3 & 2.4 \\
\hline Pain/Itch & 25 & 23.4 \\
\hline Revision surgery & 4 & 2.8 \\
\hline Total & 43 & 39.8 \\
\hline
\end{tabular}

Table-III: Comparison between pre and post-operative stress and satisfaction after ear reconstruction surgery $(\mathrm{n}=108)$.

\begin{tabular}{l|c|c|c|c|c}
\hline Pre-Operative & \multicolumn{2}{|c|}{} & \multicolumn{2}{c|}{ Post-Operative } & $p$-value \\
\hline Future Concerns & $\mathbf{n}$ & $\mathbf{0}$ & $\mathbf{n}$ & $\mathbf{\%}$ & \\
\cline { 2 - 5 } Complications & 95 & 88.2 & 43 & 39.8 & \\
Cosmetic & 98 & 91.3 & 2 & 2 & 0.00 \\
Scars & 68 & 61.8 & 3 & 2.4 & \\
Stay in hospital & 36 & 33.7 & 5 & 4.2 & \\
\hline Social inhibition & 76 & 70.6 & 16 & 14.8 & 0.03 \\
\hline Anxiety & 85 & 79.5 & 25 & 23.5 & 0.01 \\
\hline Depression & 11 & 10.1 & 4 & 3.6 & 0.02 \\
\hline
\end{tabular}

\section{DISCUSSION}

Ear defects acquired or congenital is aphysical and mental impairment that leads to compromised quality of life. ${ }^{12}$ Knowledge, experience and appreciation of every defect as unique ensureoptimum results. ${ }^{13}$ In this study congenital ear defects among participants was fifty percent, ear defects as result of ear bite was among five point five percent of participants, tumors among twelvepercent, while less than three percent of participants had ear defects due to infections almost similar results were shown in study done by Pickrell et al in which $65 \%$ of participants had congenital ear defects, 35\% developed ear defects due to dog bite, tumor among eight percent while only three percent of the participants had ear defect due to infections. ${ }^{14}$ Postoperative complications experienced by participants of this study were pain and itching among 23\%, $4 \%$ developed hematoma/bleeding, $2 \%$ faced revision surgery and only one percent developed infection. These results are similar to the results of study done by Dyson, In which 20\% developed pain and itching, 3\% developed hematoma/bleeding, $3 \%$ faced revision surgery while only $0.5 \%$ developed infection. ${ }^{15}$ Similar to the study done by Awan etal this study endeavors to highlight the amelioration of psychological effects of ear defect after reconstruction surgery. ${ }^{16}$ Similar to these results other studies done on ear reconstruction by Puatu et al, have noted that social support from family and friends plays vital role in dealing with the impact and stress of ear defect. ${ }^{17}$ Preoperatively participants of this study hadconcerns cosmetic results of the procedure, development of complications due to surgical procedure, development of ugly scar at surgical site and some of the participants were worried about prolonged stay in the hospital after the procedure which was mainly due to unaffordability by the caregivers or patient itself (here it is prudent to highlight that in our country patient or the caregiver have to bear the expenses as health insurance is nonexistent)Ali et al, in his study has similarly noted that patients undergoing ear reconstruction surgery had concerns about insufficient informational care provided to them, cosmetic results of surgery, apprehensions about difficulty in hiding the scar or healing ear and problems related to healing after surgery. ${ }^{18,19}$ In this study, $91 \%$ of patients had cosmetic concerns while $88 \%$ were worried about post operative complications but in study done by Olshinka et al. A $63 \%$ of patients had concerns about post operative complications while $59 \%$ showed to have cosmetic concerns. ${ }^{20}$ It can be noted in this study that post operatively there is improvement in these concerns as highlighted by Awan et althat post operatively self confidence of patients was improved as there cosmetic concerns were reduced with increased motivation and ability to wear ear ornaments. ${ }^{16}$ Satisfaction with surgical procedure is profound as $90 \%$ of the participants of this study wanted to opt for same procedure gain if required while $7 \%$ although not dissatisfied with surgery were not sure to go through same surgical procedure these results are in contrast to the results of study done by Steffen et al, in which only $60 \%$ of patients agreed to go through same surgical procedure. ${ }^{11}$ Pre operative assessment of mental health in this study shows that $79 \%$ of participants had anxiety while ten percent exhibited depression. Post operative assessment of mental health revealed remarkable improvement in anxiety and depression as anxiety reduced to $23 \%$ and depression among three percent of 


\section{Ear Reconstruction Surgery}

the participants. These results are similar to the results of study by Awan et al, in which anxiety was higher than depression which was remarkably reduced after surgical procedure but many had difficulty in developing confidence and coming in terms with new look as they opted to hide their ears as defense mechanism. ${ }^{16}$ Patients with ear defect feel vulnerable to ridicule by peers as a result these patients actively hide their ears and in doing so they avoid gathering and any situation that may focus attention on them consequently they face difficulty in their jobs as evident in the results of this study that pre operatively seventy percent of participants experienced social inhibition that reduced to $14 \%$ after the ear reconstruction surgery similar results have been highlighted in study by Li et al, emphasizes that patients with ear defect perceive that they are being judged therefore they try to avoid unwanted attention from peers, colleagues and employers, this social inhibition has been shown to improve after ear reconstruction surgery. ${ }^{21}$

\section{CONCLUSION}

Ear Reconstruction is a very rewarding procedure for surgeon and patients. Apart from aesthetic and functional improvement it also enhances the self-esteem of the patients.

\section{Conflict of Interest: None.}

\section{Authors' Contribution}

GA: Data collection and interpertation, SAK: Data collection, compilation and discussion, HR: Archive data search, AR: Data entry and statistical analysis, GR: Data analysis, MR: proof reading and compilation

\section{REFERENCES}

1. SclafaniAP, Mashkevich G. Aesthetic reconstruction of the auricle. Facial Plast Surg Clin North Am 2006; 14(2): 103-116.

2. Armin BB, Ruder RO, Azizadeh B. Partial auricular reconstruction. Semin Plast Surg 2011; 25(4): 249-56.

3. Steele J, Farmer E, O'Hara J. Ear aesthetics: investigation by the use of an online viral survey. Ann Plast Surg 2017; 78(3): 330-333.

4. Zilinsky I, Erdmann D, Weissman O. Reevaluation of the arterial blood supply of the auricle. J Anat 2017; 230(2): 315-324.

5. Cerci FB. Staged retroauricular flap for helical reconstruction after mohs micrographic surgery. An Bras Dermatol 2016; 91 (Suppl-1): 144-147.

6. Marx H. Die Missbildungen des Ohres. In: Henke F, Lubarsh O, eds. Handbuch der Spez Path Anatomie Histologie. Berlin, Germany: Sprin 1971; 34(1): 620-625.
7. Tanzer RC. Total reconstruction of the external ear. Plast Reconstr Surg Transplant Bull 1959; 23(1): 1-15.

8. Brent B. Auricular repair with autogenous rib cartilage grafts: two decades of experience with 600 cases. Plast Reconstr Surg 1992; 90(3): 355-374.

9. Nagata S. A new method of total reconstruction of the auricle for microtia. Plast Reconstr Surg 1993; 92(2): 187-201.

10. Horlock N, Vögelin E, Bradbury ET, Grobbelaar AO, Gault DT. Psychosocial outcome of patients after ear reconstruction: a retrospective study of 62 patients. Ann Plast Surg 2005; 54(5): 517-524.

11. Steffen A, Klaiber S, Katzbach R, Nitsch S, König IR, Frenzel H. The psychosocial consequences of reconstruction of severe ear defects or third-degree microtia with rib cartilage. Aesth Surg J 2008; 28(4): 404-411.

12. Johns AL, Lewin SL, Im DD. Teasing in younger and older children with microtia before and after ear reconstruction. J Plast Surg Hand Surg 2017; 51(3): 205-209.

13. Li D, Xu F, Zhang R, Zhang Q, Xu Z, Li Y, et al. Surgical reconstruction of traumatic partial ear defects based on a novel classification of defect sizes and surrounding skin conditions. Plastic Reconstruct Surg 2016; 138(2): 307e-316e.

14. Pickrell BB, Hughes CD, Maricevich RS. Ear Reconstruction: Partial Ear Defects. In Seminars in plastic surgery 2017; 31(3): 134.

15. Dyson ME, Orangi M, Goldberg LH, Kimyai-Asadi A. Repair of Anterior Ear Defects Using Transcartilage Island Pedicle Flaps. Dermatol Surg 2019; 45(10): 1222-1227.

16. Awan BA, Samargandi OA, Aldaqal SM, Sehlo MG. Life satisfaction and quality of life in adolescents with severe microtia: the effect of improved body image disturbance after ear reconstructive surgery with costal cartilage. Middle East Current Psych 2018; 25(2): 84-90.

17. Puatu A. The psychosocial effects of microtia on family's decision process. 2018. [Internet] Available from: https:// digitalcommons.unl.edu/honorstheses/43/

18. Ali K, Mohan K, Liu YC. Ear Reconstruction: otologic and audiology concerns of microtia repair. inseminars in plastic surgery. Thieme Med Pub 2017; 31(3): 127-132.

19. Ali K, Meaike JD, Maricevich RS, Olshinka A. Ear reconstruction: the protruding ear: cosmetic and reconstruction. InSeminars in plastic Surg Thieme Med Pub 2017; 31(3): 152-155.

20. Olshinka A, Louis M, Truong TA. Ear reconstruction: autologous ear reconstruction. inseminars in plastic surgery. Thiem Med Publish 2017; 31(3): 146-150.

21. Li D, Chin W, Wu J, Zhang Q, Xu F, Xu Z, et al. Psychosocial outcomes among microtia patients of different ages and genders before ear reconstruction. Aesthetic Plastic Surg 2010; 34(5): 570576.

22. Vilela Chagas Ferreira M, Goldenberg DC, Kharmandayan V, Gemperli R. Management of arteriovenous malformation of the ear: a protocol for resection and reconstruction. Laryng 2020; 130(5): 1322-1326. 